\title{
Effect of Competitive Strategies on Organization Performance in Relation to Sugar Industry in Kenya
}

\author{
Ibrahim Makina ${ }^{1, *}$, Judith Nabwire Oundo ${ }^{2}$ \\ ${ }^{1}$ School of Business and Economics, Kisii University, Kenya \\ ${ }^{2}$ School of Science and Crop Protection, Nairobi University, Kenya
}

Received April 29, 2020; Revised June 19, 2020; Accepted July 1, 2020

Copyright $\bigcirc 2020$ by authors, all rights reserved. Authors agree that this article remains permanently open access under the terms of the Creative Commons Attribution License 4.0 International License

\begin{abstract}
This paper takes a theoretical examination on issues and concepts of Competitive strategies and how these strategies affect organization performance in general and how it can be applied in sugar industry. Competitive strategies are; cost leadership, product differentiation and focus; the effect of performance in terms of profit increase, reduction in customer complaints, reduction in operational costs and increase in market share. The study looked at the performance of sugar industry in the world and how competitive strategies can be used for better performance of sugar industry. The purpose of the study was examining the applicability of competitive strategies in sugar industry. Desktop analysis methodology was used through meta-analysis. From the reviewed literature, it revealed that organizations that use competitive strategies realize better performance than those that doesn't. This study is relevant to the policy makers for decision making, and it is also important to the researchers as it provides a platform for further studies. It is relevant for the managers as they can apply competitive strategies in sugar manufacturing firms. It also provides a chance to the managers of different sugar manufacturing firms to compare their performance with other countries that perform relatively better in sugar sector. The study recommends that sugar manufacturing firms should use competitive strategies in order to realize better performance. In conclusion, from the reviewed literature through meta-analysis, competitive strategies have a positive impact on performance of an organization.
\end{abstract}

Keywords Competitive Strategies, Cost Leadership, Product Differentiation, Focus and Organization Performance

\section{Introduction}

Different organizations implement different strategies for different aims. These aims can be that an organization remains relevant in the industry, competes with other organizations in the industry, and gets competitive advantage and makes profits. Porter (1985) defines strategy as creating very unique positions that are very valuable to the organization and they are implemented through different activities. Wittingtine (2005) defines strategy as the direction that an organization sees in long term. The major aim is to achieve organization's objective while considering the dynamics of environment. The objective of an organization can be achieved depending on the resources that an organization has. In sugar industry, organizations that produce sugar have the capacity to achieve their goals when strategies that are formulated will be implemented fully (Gituku, Wangari \& Kagiri 2015)

There are many strategies that organizations can take to improve their performance. This paper looks at specifically competitive strategies whose proponent was Michael porter. He argues that, for an organization to have competitive advantage and increase the performance it has to apply any of the three strategies: cost leadership, product differentiation and focus. This means that it is inevitably important for sugar industry whose production is below capacity to embrace these competitive strategies. Competitive strategies refer to the wider perspective of the way, use the ability of an organization to create a competitive advantage in relation to other firms in the same industry irrespective of the size of the organization (Herbert and Deresky 1987). Pulaj, Kume Vasilika and Cipi (2015) organizations can use these competitive strategies to increase their performance, for instance, increasing profit, increasing sales, increasing market share, reduction in complaints from the customers and reduction of the operational costs. Sugar industry which is ailing in terms of performance when firms apply these strategies can improve the performance.

Porter (1980) argues out that organization that does not embrace competitive strategies for instance; cost 
leadership, product differentiation and focus strategies will be stuck in the middle. Navulur and Kofand (2015) argue that resources that an organization has are very important in achieving competitive advantage. Different organizations have different resources which can influence the performance. These resources include financial resources, human resources and the physical resources.

Organizations can have competitive advantage depending on the resources they have. The major sources of competitive advantage are cost leadership focus and product differentiation. Porter (1985) argues that there are mainly two sources of competitive advantage that an organization can take; these are cost leadership and product differentiation. When low cost of production and product differentiation are combined with the scope of any business, different market segments will be created. Mintzberg, Bruice and Joseph (1998) argue that after the combination of the two strategies for instance, cost leadership and product differentiation, the third Generic strategy will be formed (focus) Porter (1980) argues that every organization must use any of the strategies if it wants to achieve competitive advantage. If the organization chooses any of the competitive strategies and does not achieve a competitive advantage, it will be stuck in the middle.

\section{General Overview of Performance of Sugar Manufacturing Firms Globally}

The demand for sugar is on increase trend in the world. Due to the increase in demand for sugar from time to time, it is the most fertile industry to be invested in. According to Monitoring African Food and Agriculture Policies (MAFAP 2013) The major causes of this increase in demand for sugar is attributed to population increase and the expansion of industries that use sugar to produce their products such as biscuits, soft drinks, beverages to mention but few. Because the demand for sugar is high, organizations that produce sugar needed to embrace Michael porter' Competitive strategies, that is to say, cost leadership, focus and product differentiation. For example, when organizations control cost of production, they will be in position to increase their performance in terms of increased sales, profitability, reduction in operation expenses and reduction in complaints from customers.

Kegode (2015) the world's lowest cost producers of sugar are: Brazil, Australia, Thailand, China and Guatemala. These countries have invested a lot in strategies of reducing costs of production. They use irrigation, low cost of labor, high capacity utilization and efficient utilization of bi-products. Competitive Commercial Agriculture in Sub-Saharan Africa (CCAA) (Geoff Teyler) In Africa the leading sugar producing country is South Africa

Chatenay (2013) argues that some of the reasons are attributed to good performance of Brazil in sugar production including use of competitive strategies by the sugar manufacturing firm. They use cost leadership strategy which reduces cost of production, these firms use irrigation, The Brazilian government intervenes by offering loans to the farmers at relatively low interest rate which motives farmers, Most of the sugar manufacturing firms in Brazil do product diversification ethanol and farmers are paid on time with the aim of motivating them. All these strategies are aimed at reducing cost of production.

\section{General Overview of Performance of Sugar Manufacturing Firms in Africa}

Africa as a continent produces an average of 2.7 million tons per year. South Africa exports half of its sugar products. The major contributor of its good performance is the climate, high capacity utilization, low labor cost and the ability of sugar producing companies to efficiently use the bi- products. In 2004/2005 Africa produced 8.2 million tones and imported 6.6 million tones and exported 3.8 million tones. In comparison to the world performance that was 140.7 million tones and the export was 47.8 million tones. This means that most of the African countries produce sugar below the capacity. In a research that was conducted by Chidoko and Chimwai (2011) on Economic challenges of sugarcane production in the Lowland of Zimbabwe. It revealed that there are many challenges affecting cane production which include delayed payments, bad governance and poor infrastructure. These challenges that Zimbabwe faces are not different from those one that Kenya faces. Owiye, Naibei and Momanyi (2016) argue that in East Africa Uganda has been performing better in production of sugar. Recently it has been overtaken by Tanzania because of poor infrastructure, delayed payment to farmers and political interference. Tanzania is the biggest producer of sugar in East Africa. Some of the reasons for better performance include payment of farmers on time, use of competitive strategies (cost leadership) and good will from the government. This means that there is minimal government interference and when the government interferes it is through offering affordable loans to the farmers, improving of infrastructure and looking for market. These strategies are taken in order to reduce cost of production and motivate farmers.

\section{General Overview of Performance of Sugar Manufacturing Firms in Kenya}

According to (KSI 2005) Sugar cane is grown in the western part of Kenya and some parts of coast region. Sugar industry in Kenya is dying because most of the sugar producing companies is struggling to survive. Mumias at one time was the largest and booming in terms of producing sugar is on its knees. This is because of corruption, mismanagement, lack of accountability, constant wars with the neighboring companies such as 
Butali, Nzoia and West Kenya companies. Makina and Kenga'ra (2018) argue that 85 percent of cane is grown by the out growers and the remaining 15 percent is supplied by the respective organizations through nucleus. This means that the major cane supplier for these organizations is the out growers. It sends an implication that organizations cannot survive without the out growers. Unlike other world largest producers like Brazil, China and South Africa have invested a lot in irrigation, product diversification, payment of farmers on time, offering farmers affordable loans and improvement in infrastructure. In Kenya many organizations struggle with cane poaching. (KSI 2005).

Sugar industry in Kenya is an industry that is struggling to survive because of problems it is facing. These problems include but not limited to, a lot of pressure from COMESA, accumulated unpaid debts, political interferences, competition and wars among the sugar producing organizations and corruption (Makina \& Kenga'ra 2018). The government of Kenya has tried to intervene to bail out these organizations. The Government of Kenya has come up with many strategies in order to save the industry. These strategies include the following; writing off loans, improvement of infrastructure, constant push for the extension of COMESA protection, settling pending loans for sugar companies. According to (KSI 2005) these Government efforts have not made a significant change in terms of the organizations' performance. In fact, the performance is still low. Most of these industries are operating below their capacity which include Mumias, Nzoia, Butali, West Kenya, Sony Sugar company, Chemilil, Muhoroni all of them operate below the capacity, constant increase in the prices of sugar as compared to COMESA prices and the world sugar prices. Political interference is one of the major headaches because politicians push for farmers to be paid higher prices per tonnage at the same time they want the prices of sugar to remain low. They push for this with an aim of scoring politically. This makes the organization to be stuck in the middle because they cannot control cost of production capacity. The best example is Mumias Sugar Company that one time was performing very well, now it is on its knees.

If an organization that cannot control the cost of production, it will be hard for it to survive in the business world. According to Michael Porter (1985) Organization should be a cost leader for it to gain a competitive advantage. This means that it has to reduce cost of production through different ways for example, reducing operational costs for instance, downsizing workers, avoiding unnecessary costs of production. This is contrary to the sugar producing organizations in Kenya where the cost of production has steadily increased.

Most of the Sugar producing organizations are stuck in the middle because they implement some of the Competitive strategies but they still don't achieve the competitive advantage as compared to other COMESA member countries. In fact, they still produce below capacity. These organization such as Mumias sugar company carries out downsizing of its employees, but the cost of production is still high. According to (KSI 2015) sugar industry has been struggling to survive because of many reasons which include lack of accountability, poor management financial mismanagement by the managers. According to Monitoring Africa Food and Agricultural policies (MAFAP, 2013) Kenya sugar industry has failed to control the cost of production. This means that sugar industry in Kenya cannot compete favorably with other countries producing sugar in the region for example Sudan, Ethiopia and South Africa that are the leading countries in producing sugar in Africa and Brazil, China, and India who are the leading producers of sugar in the world. According to porter (1985) Argues that organizations should apply any of the competitive strategies so that they can realize competitive advantage in the industry. This means that Kenya has a long way to go. It has to look for ways of reducing cost of production.

According to (KSI 2015) Food Agriculture Organization (FAO) and Business Monitor International, Report forecast sugar production reveals that the cost of producing sugar in Kenya is twice expensive than other countries producing sugar in the world. The cost of production per tonnage in Kenya has risen from $\$ 415$ to $\$ 950$ it is more than the cost of production in Egypt and COMESA member countries. This means that sugar producing companies cannot compete favorably with other countries producing sugar because the cost of production is always high. This is one of the reasons why the government of Kenya has endlessly pushed for COMESA protection to be extended for another term.

Despite many strategies that Kenyan government is doing to bail out sugar industry the organizations are still producing below capacity. For example, in Kenya the government has tried a lot by pushing for the extension of COMESA protection, improvement of infrastructure, writing off loans. With all these efforts the sugar industry is still producing bellow it's capacity. This means there is need to explore causes of poor performance. (KSI 2015).

\section{Empirical Literature Review}

\subsection{Cost leadership and Organization Performance}

Organization that has aligned cost leadership strategy and competitor orientation in the long run will have a competitive advantage. According to the research that was conducted by Kaliappen and Hilman Haim (2013) in Malaysia concerning the enhancing the organizational performance using strategic Alignment of cost leadership strategy and competitor orientation. The researcher used a survey research design of 54 hotels that implemented cost leadership strategy. Findings indicated that cost leadership strategy has a significant effect on the organization's 
performance. The performance increase can be through increasing market share and profitability and reducing in customer complaints. The research bridges the gap by showing the significance alignment of cost leadership strategy and competitor orientation in the hotel industry. This can also be borrowed by sugar industry. However, managers should also embrace other competitive strategies such as product differentiation and focus in order to increase the performance in terms of increasing profit and extending the market share.

Organizations use cost leadership strategies as a tool for bargaining with the suppliers. This is usually done with the aim of reducing cost of production. Altuntas (2014) conducted a research by determining the relationship between the individual forces, competition and functional strategies and the organizational performance in restaurant businesses. The researcher used questionnaires without sampling the restaurant in Istanbul Turkey. Findings showed that competitive strategies, particularly cost leadership strategy is key to bargaining power of suppliers. Product differentiation specifically branding image attracts consumers and can be used as a source of competitive advantage. The researcher also argues that human resource is a key to performance. The research contributes to how to appreciate cost leadership strategy, product differentiation and human resource by telling how they can be used to improve the performance of an organization. However, the researcher never looked at the effect of focus strategy (Market niche) which can also increase the performance of an organization. Focus is very important because it increases the total sales after new markets have been established. These strategies can also be researched in sugar industry.

Agricultural businesses use competitive strategies to increase the performance of an organization. Navulur \& Kofand (2015) assessed the impact of competitive strategies on the competitive advantage on performance of an organization in India. Using a cross-sectional research design; they distributed the questionnaires to 53 farmers. Findings showed that competitive strategy has positive impacts on the organizational performance. Findings indicated that cost leadership strategy has a bigger impact on the performance of agricultural businesses than focus and product differentiation. This means that organizations that invest a lot in reducing the cost of production and distribution stand high chances of increasing their performance including profit increases. The research contributes by emphasizing that it is important for an organization to invest in generic strategies so as to increase performance. However Generic strategies can also be applied in sugar industry.

Cost leadership strategy is a way of reducing or controlling costs of production, which is used in different organizations to improve their performance. Nyauncho \& Nyagara (2015) assessed the effect of cost leadership strategy on the performance of liquefied petroleum gas in companies in Eldoret, Kenya. The researcher used a survey research design with target population of 175 that comprised 10 station managers, 40 Departmental heads, 20 supervisors and 105 employees. Findings showed that there is a positive correlation between cost leadership strategies and the performance of an organization. Findings showed that generic strategy enables the company to reduce prices of products after reducing the cost of production in terms of sales volume, profits and increases in service delivery, reduction in operational cost and wastage. The contribution of the research is that the recommendation that organizations should carry out intensive market research to identify gaps in the market and fill those gaps. Cost leadership strategy is a very important strategy in improving the organization performance but other generic strategies can also be a source of increasing performance. When these three strategies are combined can make performance of organization improve. (Cost leadership, product differentiation and focus)

Competitive strategies are major contributors to the performance of the organization. Atikiya, Mukulu \& Waiganjo (2015) conducted a research by investigating the effect of cost leadership strategy on the performance of manufacturing firms in Kenya, using survey research design questionnaires with the target population of 131 firms from key sub-sectors that are located in Nairobi. They found out that there is a positive correlation between cost leadership and the performance of the organization (manufacturing firms). The research contributes by recommending that firms should implement Generic strategies specifically cost leadership strategy so that it can achieve better performance. However, the research emphasizes cost leadership strategy but does not look at other strategies (focus and product differentiation) that can also contribute to better performance if used together. The research emphasizes on agriculture firms while ignoring sugar industry.

There is a close relationship between cost leadership strategy and quality management and financial performance of an organization. Kurt \& Zehir (2016) conducted a research by investigating the relationship between cost leadership strategy, total quality management applications and firm's financial performance. Researchers used survey research design using the respondents of 142 managers of big firms. Findings showed that cost leadership is positively correlated to the financial performance of the firm. However, the researcher looked down upon other generic strategies that are also in position to improve the organization performance. These strategies are; cost leadership, product differentiation and focus. The researcher also never looked at sugar industry

Birjandi, Jahromi and Somaye. (2014) conducted a research in Tehran on the effect of cost leadership strategy on Return on Asset and future performance in firm's Tehran Security Exchange (TSE). Through using 45 firms in Tehran Security Exchange in a survey research design 
finding indicated that firms that used cost leadership strategies had a positive relationship between the ratios of sales to capital expenditure with increase in sales. The research contributes positively in the performance of the organization. However, managers should embrace cost leadership strategy. They should also embrace other competitive strategies like focus and product differentiation that will also increase the performance of an organization. It will not only increase profitability of an organization but also increase market share (focus) and reduce customer complaints (product differentiation) it can also be applied in sugar industry so as to increase organization performance.

Competitive strategies increase performance of an organization by increasing the profits, increasing the market share and reducing the customer complaints. (Kinyuira (2014) conducted a research in Murang'a, Kenya. The researcher examined the effect of Michael Porter's Generic competitive strategies that were adopted by SACCO's in Murang'a County on the performance. The findings indicated that there is positive significant effect of competitive strategies: cost leadership, focus and product differentiation on performance of SACCO's. The study contributes to understanding the Generic strategies and SACCOs that pursue generic strategies achieve superior performance. This means that performance can be improved in terms of profit increase, market share increases and reduction in consumer complaints. However, managers of the sugar producing companies can also use the generic strategies to increase their performance.

Most of the organizations use cost leadership strategies and product differentiation to have a competitive advantage as compared to their competitors. Arasa and Gathinji (2014) examined the relationship between competitive strategies such as cost leadership, product differentiation and focus with the organization performance among firms in telecommunications industries in Kenya. When using survey research design of 63 workers of telecommunication, findings indicated that cost leadership and product differentiation are the major strategies used by the organizations. The study contributes by arguing that an organization must have low cost of production and workforce committed to low cost strategy so as to have a competitive advantage. However, the organization should embrace other competitive strategies including focus so that new markets can be utilized in the long run and increase market segments like geographical markets.

A competitive strategy has a positive impact on the performance of sugar manufacturing firms. Khalaji (2014) carried out a research on the relationship between competitive strategies and technological development in India. Findings revealed that there is a positive relationship between competitive strategy and technological development. This means that competitive strategies have a positive correlation with the performance of an organization. Similarly, in a related study, Nazir, Jariko and Junejo (2013) conducted a research on factors affecting sugar cane production in Pakistan. Findings revealed that high cost of production, low prices of output and delayed payment to the farmers were major contributors to the poor performance of sugar industry in Pakistan. On the other hand, related study was conducted on performance of sugar manufacturing firms. Chidoko and Chimwai (2011) conducted a research on economic challenges of sugar cane production in the lowland of Zimbabwe. It revealed that there are many challenges affecting cane production which include delayed payment, bad governance and poor infrastructure. This means problems that sugar manufacturing firms face in Africa are the same. Unless these problems are addressed, production will continue being very low.

Sugar industry is very reluctant in implementing Michael Porter's competitive strategies and this could be one of the reasons as to why the industry has stagnated for a long period of time without making some positive changes in terms of performance. Kabura (2014) conducted a research by assessing the impact of liberalization and competitive strategies that are adopted by sugar processing firms in Kenya. Descriptive cross-sectional survey design was used in 9 sugar processing firms in Kenya and census was used of 3-5 managers in every company. Findings indicated that there was slow adoption of competitive strategies which include cost leadership, focus and product differentiation. The research contributes by embracing competitive strategies and innovation through the use of information technology in production. However, the manager should look for ways of convincing the organization management and stakeholders to use all generic strategies including focus that will in the long run widen the market share and decrease consumer complaints.

Cost leadership strategy is that the organization uses low cost of production as compared to other organizations in the same industry. This strategy makes an organization to have a competitive advantage over the competitors in the industry. Amali. (2015) looks at cost leadership strategy as a way in which an organization produces products and services at a lower cost and at the same time distributes those products at a lower cost. Organizations that use different strategies to increase their performance usually achieve some of the objectives. Wachiye conducted a research by assessing the strategic responses by different companies in the sugar industry in Kenya specifically Mumias sugar company and how companies are prepared for the implementation of COMESA Free Trade Agreement. Cross sectional descriptive research design of 11 sugar companies in Kenya was used. Findings showed that major challenges of the sugar industry were high cost of farm inputs, uneconomical size of farmers plots, weak management of farmers institutions and lack of diversification of products. The research contributes to the study by suggesting how strategic responses are very 
important in reducing the cost of production. This is in agreement with Michael porter's (1985) argument that organizations should strive to produce products and services at a lower cost so as to have a competitive advantage in the industry. It also means that organizations or sugar industry should embrace strategic responses on the environment. However, organizations can also implement other competitive strategies such as product differentiation and focus in order to achieve competitive advantage.

Competitive strategies can be used to spur performance of sugar industry. Wekesa (2014) investigated effect of competitive strategies on how it can affect the performance of sugar industry in Kenya. The researcher used descriptive research design, census and the target 108 respondents from 9 sugar companies in Kenya. Findings showed that Generic strategies have positive impact on the performance of sugar producing companies. When Generic strategies are implemented, the performance of an organization will increase. The performance will be increased through profit increases, increase in market share and reduction in customer complaints. However, managers should embrace generic strategies and they should also embrace other factor that contributes to the increase in the performance of an organization.

\subsection{Product Differentiation on Organization Performance}

Just as human beings want to be unique and be seen different, the organizations also try to be unique and do things differently. Doing things differently and producing products and services that are unique in terms of colour, size, shape is what is called product differentiation. In order to produce products that are different and unique, the organization must have resources that cannot be imitated easily by the competitors. Michael Porter (1985) argues that an organization that produces goods unique than its competitors can charge higher prices and will not raise complaints from customers because the customer's loyalty will have achieved a competitive advantage. This will increase the performance of an organization. This will increase the performance of an organization through higher profits and less complaints from customers.

Some organizations implement competitive strategies, specifically product differentiation but they do not experience any significant increase in performance. This means that they are stuck in the middle. Mohammed and Aliqah. (2012) conducted a research by investigating the relationship between differentiation strategy and organization performance in Amanan stock exchange in Jordan companies. Researcher used 33 industrial companies in Amanam stock exchange, using survey research design. Findings showed that, differentiation strategy has no significant effect on performance of such companies. The study contributes by suggesting the incorporation of different dimensions of product differentiation strategies so as to improve the performance. However different managers of different organizations should use generic strategies to increase the performance. For example, cost leadership strategy and focus depart from dwelling on product differentiation. The researcher dwelt on stock exchange alone and never looked at other organizations such as sugar industry to come up with the conclusion.

Performance of an organization to a large extent depends on the strategy it takes. For example, Michael porter's competitive strategy has three strategies: cost leadership, focus and product differentiation. Stanislaw Lenka \& Komar (2013) conducted a research in Czech Republic on the determinants of successful differentiation strategy. The researcher used survey design of 114 enterprises that used differentiation strategy as a strategy formation. Findings revealed that the success of the enterprise significantly depends on the level of strategy formation. The research contributes by recommending that managers should formulate strategies from the global point of view. However, the researcher never came out clearly on how the differentiation affects the success of the organization. The researcher looked at differentiation strategy and ignored other Michael porter's generic strategies: focus and cost leadership. It did not look at the sugar industry hence need to be looked at.

Product differentiation as one of the Michael porter's generic strategies has a significant impact on the performance of an organization. According to the research that was conducted by Febrianti \& Dora (2013), it investigated the impact or development of product differentiation and customer relationship management to enhance creativity and innovation efforts Batik image affecting marketing performance in Indonesia. The researcher used descriptive research method. using a sample size of 200 small micro-enterprises in Cirebon east Java. Findings showed that product differentiation had the most positive significance to the market performance. The research contributes by encouraging managers to embrace product differentiation when they want to achieve a set target in terms of performance. However, there is an need to look at other Michael porter's generic strategies, cost leadership and focus that also affects performance of the organization.

In some industries, product differentiation has relatively little impact on the performance of an organization. Aykan \& AKsoylu (2013) conducted a research by investigating the effects of competitive strategies and strategic management accounting techniques on the perceived quantitative and qualitative performance of medium and large size business in Kayseri Turkey. The researcher used 229 accounting managers by using a cross-sectional research design. Findings showed that the relationship between the product differentiation and perceived performance is low. The research contributes by suggesting the use of other methods that can help an organization to 
realize higher performance. However, there is need to look at other Michael porter's generic strategies also determines the performance. They include focus and cost leadership.

Michael porter's competitive strategy, product differentiation has impact on the performance of an organization. The research conducted by Shawifu \& Muhammed (2013) investigated the impact of product differentiation on the performance of oil producing companies in Ghana. Research was done through the use of cross-sectional research design and the sample size of 15 oil manufacturing companies in Ghana, among these companies 14 were private owned and 1 was government owned. Supervisors, H.O.D and directors were the major target and they were the only ones that filled questionnaires. The results of the research showed there was a positive relationship between the product differentiation and the profitability of the. This research contributes by encouraging the organization to go ahead and differentiate more products so as to increase performance of an organization. At the same time, it encourages organizations to make awareness of the product with an aim of increasing performance. However, there is a need for managers to use other Michael porter's generic strategies: cost leadership and focus strategies to increase profitability, reduce consumer complaints, increase sales and market share.

Product differentiation can be used as a source of good performance; increase in sales, increase in market share, reduction in complaints and increase in profitability. Dirisu, Oluwole \& Ibidunni (2013) examined product differentiation as a tool of competitive advantage and optimal organization performance in Unilever Nigeria (PLC). The research design that was used was survey. The researcher targeted household consumers because they can compare with the products of the competitors. They also targeted the workers of Unilever Company Nigeria. The sample was 323 respondents from schools, banks and shopping malls. The results of the research showed a positive correlation between higher products quality and the sales growth of the organization. It also revealed that there was a strong relationship between new products, innovation and customer satisfaction. There was positive relationship between the design of a product and sales growth. From the results, it means that product differentiation has a strong impact on the performance of the organization because sales did increase, customers were satisfied after consuming products. However, managers should use other Michael porter's generic strategies like focus and cost leadership strategies to increase performance of the organization.

Differentiated products can be charged higher prices than the undifferentiated products. Estenban. Brens (2014) conducted a research in Latin America and determined the impact of differentiation strategies on emerging markets. The research was conducted using survey and interviews using the sample size of 66 agribusiness-based countries in eight countries of Latin America. The results revealed that differentiation strategy contributes positively to the performance of the organization. The contribution of the research is that organizations should implement product differentiation strategy for better performance. However, managers of different organizations should use other Michael porter's generic strategies as a source of competitive advantage and a tool for increasing performance.

Product differentiation can be used by small and medium enterprises as a tool to increase their performance. Sukesti, Nurhayati and Karim. (2014) analyzed influence of product differentiation and government regulations on the small and medium enterprises in Semarang Indonesia. Research was done using survey research design and the questionnaires were distributed to 100 respondents. Results revealed that product differentiation has a positive impact on the performance of small and medium enterprises and the government regulations. The research is important because it suggests that when innovation is used, it will change the welfare of the society. However, managers should implement other Michael porter's generic strategies (focus and cost leadership that leads to higher performance.

When products are differentiated, they become appealing to the customers. And when combined with innovation, they create a significant impact on the performance of an organization. Cemal zahir (2015) determined the role of product differentiation strategy and innovation on performance in Turkey. Survey research design was used the research targeted 199 middle and senior managers in 331 middle and large-scale firms operating in manufacturing industry operating in Turkey. The research revealed that product differentiation and innovation has a mediating impact on the organizational performance. The research shows how product differentiation and innovation are keys to the performance of an organization. However, managers of other industries like sugar industry can also apply them for better performance. Managers should also apply other Michael porter's generic strategies (focus and cost leadership) so that they can realize better performance such as sales increase, increase in market share, reduction in complaints from the customers.

Almost every organization uses Michael porter's competitive strategies with an aim of improving the performance. Some use product differentiation so as to have a competitive advantage. Koya (2015) assessed the impact of Generic competitive strategies on performance of small and medium enterprises in Turkey. Survey research design was used on the target 70 small and medium enterprises that were drawn from Turkish machinery and equipment manufacturing industry. The research revealed that product differentiation has power to improve the performance of small and medium enterprises. The research encourages the use of product differentiation for the better performance of small and medium enterprises. However, managers are encouraged also to apply other 
Michael porter's generic strategies such as cost leadership and focus. When the three generic strategies are applied together, the organization will have better performance than one strategy.

Combination of Michael porter's generic strategies (cost leadership, product differentiation and focus) can give an organization better performance. Pulaj, Kume \& Cipi. (2015) determined the relationship between competitive strategies and organization performance in construction firms in Albania. Simple random technique was used to select 110 samples of companies. Research revealed that cost leadership and product differentiation influence the performance of the organization specifically in construction firm. However, managers should not only bank on the two strategies (cost leadership and product differentiation) but also exploit new markets and in the long run performance will be improved. These strategies can also be applied by other industries like sugar industry

When products are differentiated, meaning that they have different features than the competitors' products including colour, size, quality, which will impact the way consumers perceive them. This will make consumers buy them even when the prices are increased consumers may not complain because of the satisfaction they drive from them. Marjani \& Keshavarzi (2015) surveyed the influence of differentiation strategy on gaining competitive advantage in Tehran (Iraq) the researcher used a descriptive research design with a target population of 95 respondents that were collected from the experts and managers of rare perfumes importers. Findings showed that that differentiation strategy has a positive effect on gaining a competitive advantage in the market niche. The research suggests that managers should attend courses that will make them know customer need. However, managers should also apply other Michael porter's generic strategies such as cost leadership, product differentiation and focus so as to realize good performance. When the three strategies are used together the organization will have competitive advantage in the industry over the key competitors.

Global markets can be utilized penetrated when Michael porter's competitive strategies are implemented more so product differentiation and focus. Kingoo (2015) investigated the effect of product differentiation strategy on market share of the tea factories in Kenya. The research was conducted using cross-sectional survey design using a population of 72 tea export firms in Kenya. Findings showed that extent of product differentiation for the value dated products was higher than the pricing. It discovered that product features were the most adopted strategy. The research suggests Kenya tea export firms should adopt differentiation that will make them compete favorably in the global market. However, managers should embrace other Michael porter's strategies such as focus and cost leadership that can act as a competitive advantage when penetrating the global market.

Product differentiation makes customers get satisfied and become very loyal to the organization because of the features on the products. It also makes customers become curios and want to test the product. This leads to increase in market share Kireru, Ombui and Omwenga (2016) established the influence of product differentiation strategies in achieving competitive advantage in commercial banks in Kenya. Descriptive survey research design was used and 100 respondents comprised supervisors, staff working at the Equity bank headquarters (Nairobi) were selected. Findings showed that the major contributor of the high profits that Equity bank gets is associated with giving customers products to their satisfaction. The research suggests continuous product differentiation so as to continue increasing organization performance. Recommends the following products: ATM, training, consulting, loan facilities, Agency banking and fund transfer services. However, managers should use other Michael porter's generic strategies such as focus and cost leadership strategies that will also lead to increase in performance.

\subsection{Focus Strategy on Organization Performance}

According to Michael porter (1985), it says that that organizations can have competitive advantage by identifying a market niche. When the organization decides to concentrate on certain group of customers, geographical market or a certain product line is referred to as business niche. An organization that identifies such market and has not been saturated will have competitive advantage. Extension of market may not necessarily mean increase in profits but increase in the market share, and in the long run these market shares would lead to increase in profits. Mbithi, Muturi and Rambo (2015) conducted a research by investigating the effect of market development strategies on performance in sugar industry. The research looked at two factors; developing new market and extending the market geographically. The researcher used a model where the market development strategy indicators are regressed on performance measures. Findings indicated that the outcomes that extended to new regions and developed new markets does not lead to increase in profitability. Increases in market share would eventually positively affect profitability. Rebranding, promotions, different packages makes organizations to penetrate into new markets. The research contributes significantly to the current marketing strategy literature by examining how two aspects of marketing strategies relates differently when measuring performance in sugar industry. However, managers should apply other Michael porter's strategies when determining performance of sugar industry. 


\section{Conceptual Framework}

Independent Variable

Competitive Strategies
Dependent Variable

Organization performance

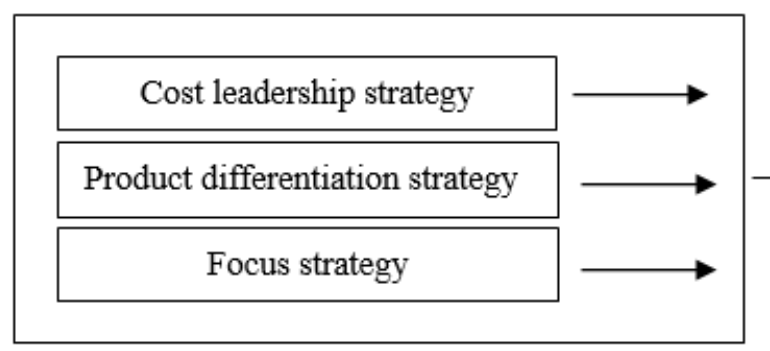

Source: Self Conceptualized 2020
Independent Variable is Competitive strategies which include cost leadership, product differentiation and focus strategy. They are the inputs that an organization puts into practice while dependent variable is the organization performance it is measured in terms of; increased profitability of an organization reduced customer complaints and reduced operational expenses.

\section{Discussion}

Most of the findings agree with the hypothesis that cost leadership as part of Michael porter's generic strategy affects positively the performance of an organization. According to the findings of Wachiye (2012) when he assessed the strategic response by different companies in sugar industry in Kenya, he concluded by saying that it is due high cost of farm inputs that makes companies to realize low profits. Kalliapen and Hilman (2013) research that was conducted in Malaysia using 54 hotels on the enhancement of organizational performance and strategic alignment of cost leadership strategy showed that there is positive significant effect on organization performance. Cost leadership strategy has a positive significant effect on the performance of telecommunication industry in Kenya. This is proved by the research that was conducted by Arasa \& Gathinji (2014) the research, which was about the relationship between competitive strategies on organization performance in telecommunication industry. Kabura (2014) researched on impact of liberalization and competitive strategies adopted by sugar companies in Kenya and found that there is positive effect of cost leadership strategy on bargaining power of suppliers.

There is an agreement that cost leadership strategy has a positive effect on the performance of sugar industry in Kenya. Wekesa (2014) findings showed that concerning the research on effect of competitive strategies on how it affects performance of sugar industry in Kenya. Navulur \&. Kofand (2015) argue that strategies affecting performance on agri-business organization. Findings showed positive effect of cost leadership strategy on the performance of agri-business. Nyauncho \& Nyagara. (2015) confirmed through the research that was conducted on generic strategy has positive impact on organization performance. This research was conducted in liquidified petroleum gas in Eldoret, Kenya. Atikiya, Mukulu \& Waiganjo. (2015) showed that cost leadership strategy has positive impact on manufacturing firms in Kenya. Kurt \& Zehir (2016) showed cost leadership has positive impact on financial performance.

For differentiation strategy, some researches do not agree with the hypothesis that there is positive effect of differentiation strategy and the organization performance. Mohammed \& Alqah (2012) conducted a research on the effect of product differentiation in stock exchange performance. The findings revealed that there is no positive relationship between the two.

Differentiation strategy has a positive impact on organization performance. Differentiation strategy has impacts on the market performance. From the research that was conducted by Fabrianti \& Dora. (2013) it showed that differentiation strategy has a positive impact on marketing performance. Research conducted by Shawifu. \& Muhammed. (2013) also showed that product differentiation has appositive effect on the organization performance. Dirisu, Oluwole. \& Ibidunni (2013) showed that product differentiation can be used as a tool of competitive advantage and optimal in the organization such as Unilever companies. Research conducted in Nigeria Unilever Company showed a positive effect of product differentiation on the company's performance in terms of sales increase. The success of enterprise depends on the strategy taken. Stanislau Lenka \& Komar (2013) findings showed that differentiation strategy has a positive effect on the performance of an enterprise. Aykan. \& Aksoylu (2013) findings showed that there is positive effect of differentiation strategy on the performance of medium and large size business in Kayseri. Turkey. Sekesti, 
Nurhayati \&Karim (2014) while analyzing the influence of product differentiation, government regulations affect performance in Semarang Indonesia, findings revealed that there is positive effect of differentiation strategy on the organization performance. Cemal zahir (2015) while determining the role of product differentiation and innovation on the small and medium enterprises in manufacturing industry in Turkey. The findings revealed that there is positive relationship between differentiation strategies and innovation on the performance of small and medium enterprises.

While Kaya (2015) assessed the impact of generic strategies on performance of small and medium and enterprises in Turkey, findings revealed that there is a positive impact of product differentiation on the performance of small and medium enterprises in Turkey. Pulaj, Kume \& Cipi. (2015) while determining the relationship between competitive strategies and organization performance on constructions firms in Albenia. Findings showed that there is a positive relationship between product differentiation and construction firms in Albania. Kashavarzi (2015) surveyed the influence of differentiation strategy on gaining competitive advantage in Tehran (Iraq). Findings showed that differentiation strategy dimensions have a positive significant impact on gaining market niche. Kingoo (2015) investigated effect of differentiation strategy on market share of the tea factory firms in Kenya. Findings showed that there is there is positive impact of differentiation strategy on the performance of tea factories in Kenya. Kireru, Ombui. \& Omwenga (2016) established the influence of product differentiation strategies in achieving competitive advantage in commercial banks in Kenya. Findings revealed that there is positive impact of product differentiation on commercial banks.

While Mbithi, Muturi \& Rambo (2015) investigated the effect of market development strategies on performance in sugar industry, findings showed that outcomes that extends to new regions and developing new markets does not lead to increase in profitability, increases in market share would eventually affect profitability. Rebranding makes an organization to penetrate into new markets.

It is assumed that Michael porter's competitive strategies (cost leadership, product differentiation and focus) have a positive impact on organization.

\section{Conclusions}

Michael porter's competitive strategies: cost leadership, product differentiation and focus have significant effects on the organization performance. From the reviewed literature it is evident that competitive strategies have a positive correlation with the performance of an organization. Different industries use these strategies to increase performance in terms of profitability, increasing market share, reducing operational costs and consumer complaints about the product. Organizations also use competitive strategies as a source of competitive advantage over the competitors in the same industry. In sugar industry there is need to do a lot so that positive performance can be realized. When three Michael porter's strategies are used together, it can lead to better performance. This study has some limitations; The study only looked at intensive literature review but did not collect or analyze data from the ground, the study also has a limitation of looking at performance of sugar industry in different countries with different climatic conditions which can also affect performance of an organization. This study recommends that sugar manufacturing firms should adopt competitive strategies in order to remain relevant and competitive in the market. It also recommends that further research should be done because data will be collected and will not only depend on the empirical literature reviewed.

\section{REFERENCES}

[1] Aykan. E. \& Akysoylu. S. (2013). Effects of Competitive Strategies and Strategic Management Techniques on Perceived Qualitative and Quantitative Performance of Medium and Large Size Business in Keyseri Turkey.

[2] Arasa.R. \& Githinji. L. (2014). Relationship between Competitive Strategies \& Organization Performance Among Firms in Telecommunications Industry in Kenya.

[3] Atikiya. R. Mukulu. E. \& Waiganjo (2015).Effect of Cost Leadership Strategy on the Performance of Manufacturing Firms in Kenya: Journal of Management ISSN 2312-9492

[4] Birjandi. H. Negar. M. Jarhomi \& Darabi. A.S (2014).Effect of Cost Leadership Strategy on ROA and Future Performance in the Firms Tehran Security Exchange (T.S.E): Research Journal of Finance and Accounting ISSN 2222-1697(paper) Vol. 5. no. 7.

[5] Brakaj. P.E., Kume. K. \& Cipi. A. (2015). Relationship Between Competitive Strategies and Organization Performance, Testing Applicability of Porter's Generic Strategy in Construction Firm.

[6] Cemel. Z. (2015). Role of Differentiation Strategy and Innovation on Performance

[7] Chateney, P. H. (2013) Government Support and Brazil Sugar Industry.

[8] Chidoko, C. \& Chimwai. (2011) Economic Challenges of Sugar cane Production in the Lower land of Zimbabwe. International Journal of Economics and Applied Research 2(5), 1-13.

[9] Dirisu. J.I. Oluwole. \& Ibidunni. O.S. (2013). Product Differentiation as a Tool of Competitive Advantage and Optimal Organizational Performance: European Scientific Journal Dec.2013 Edition Vol. 9 No.34.ISSBN:1857

[10] Febrianti R.A.M \& Dora. M.Y (2013). Development of 
Product Differentiation and Customer Relationship Management to enhance Creativity and Innovation efforts Batik Image Affecting Marketing Performance: The $10^{\text {th }}$ International Conference on Asia Pacific Business Innovation \& Technology Management.

[11] Henry. M. Bruice. A. \&. Joseph. L (1998) Safari. Guided Tour through the Wilds of Strategic Management. Kenya's Sugar Industry (2005)

[12] Kaliappen. N. \& Hilman. H. (2013). Enhancing Organizational Performance Through Strategic Alignment of Cost Leadership Strategy and Competitor Orientation in Malaysia: Asia Journal Social Sciences, Vol.10 No.10.

[13] Kinyuira. D. (2014). Assessment of the Effect of Porter's Generic Competitive Strategies Adopted by SACCO'S in Murang'a County on SACCO's Performance.

[14] Kaburu. M.E. (2014). Impact of Liberalization and Competitive Strategies that are Adopted by Sugar Processing Firms in Kenya.

[15] Kaya. N. (2014). Generic competitive strategies and firm performance in small and medium sized enterprises.

[16] Kingoo. J.M. (2015). Effect of Differentiation Strategy on Market Share of Tea Factory Firms in Kenya: College of Humanities and Social Sciences (CHHS).

[17] Kegode, P. (2015) Sugar in Mozambique: Balancing Competitiveness with Protection.

[18] Khalaji, A. (2014) The Analysis of Technological Capabilities in Sugarcane Industry: Case Study of Salman Firm. Cultivation and Industry Company. Indian Journal of Fundamental and Applied life Sciences, 4, 965-972

[19] KURT.A.\& ZEHIR.C.(2016). The Relationship Between Cost Leadership Strategy, Total Quality Management Applications and Firms Financial Performance: Dogus univeritesi Dergisi, 17(1)2016,97-110

[20] Kireru. N.J. Ombui. K. \& Omwenga. J. (2016). Influence of Product Differentiation Strategies in Achieving Competitive Advantage in Commercial Banks in Kenya: International Journal of Business and Law Research 4(2):40-52

[21] Mohammed. K \& Aliqah A. (2012). Relationship between differentiation strategy and organization performance: Journal of. Economics, 3(1):7-11(2012)

[22] Monitoring African Food and Agricultural Policies MAFAP Analysis of Incentives and Disincentives for Sugar in Kenya (2013)
[23] Marjani. A.B. \& Keshavarzi (2015). Influence of Differentiation Strategy on Gaining Competitive Advantage: Journal UMP Social Sciences and Technology Management Vol. 3 Issue. 1, 2015

[24] Makina, I. \& Kenga'ra, R. (2018) Managing Strategic Change of an Organization Performance: A case of Nzoia Sugar Company Kenya. Universal Journal of Management, 6 (6) $198-212$

[25] Mbithi. B., Muturi. W. \& Rambo. C. (2015). Effect of Market Development Strategies on Performance in Sugar Industry: International Journal of Academic Research in Business and Social Sciences 2015. Vol. 5, No. 12 ISSN: 2222-6990

[26] Nazir, A. J. (2013) Factors Affecting Sugar cane Production in Pakistan. Pakistan Journal of Commerce and Social Sciences 7 (1), 128-140

[27] Ngari. J.A (2015). Kenya Sugar Industry: East Africa's bitter-sweet.

[28] Navulur. K.S. \& Kofand. A. (2015). Impact of Generic Strategies on Competitive Advantage in Agricultural Business.

[29] Nyauncho. M.J. \& Nyagara. I.N. (2015). Assessment of the Effect of Cost Leadership Strategy on the Performance of Liquidified Petroleum Gas Company in Eldoret, Kenya: International Journal of Business and Management Invention ISSN (online)

[30] Owiye, P. Naibei \& Momanyi, G. (2016) Effect of Trade Liberation on Performance of Sugar in Kenya: The case of Government Owned firms. European Scientific Journal, 12(13)

[31] Porter, M. (1980). Competitive Strategy: Techniques for Analyzing Industry and Competitors. New York; free press.

[32] Shawifu. A.B.\& Muhammed. A. (2013) Effect of Product Differentiation on Profitability in Petroleum Industry in Ghana; European Journal of Business and Innovation Research Vol. 1, No.4 pp 49-65

[33] Sukesti. F., Nurhayati \& Karim.A.(2014). Influence of Product Differentiation and Government Regulation to the Performance of SME's with Working Capital as Moderating Variable: South East Asia Journal of Contemporary Business Economics \& Law Vol. 5 Issue 2 (DEC) ISSN 2289-156

[34] Wachiye. R.M. (2012). Strategic Responses by Companies in Sugar Industry in Kenya to Implementation of COMESA Free Trade Agreement. 